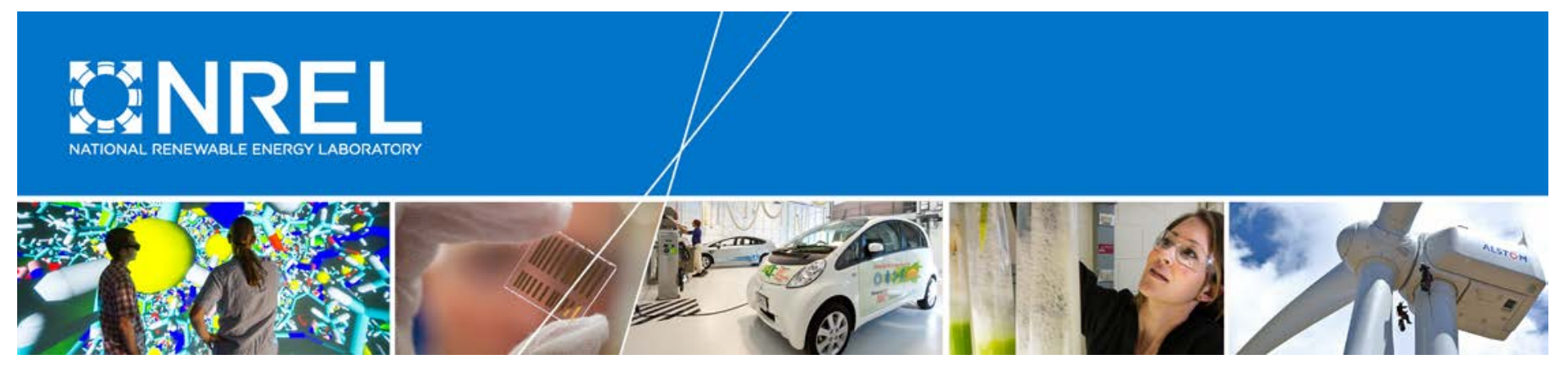

\title{
Using Measured Plane-of-Array Data Directly in Photovoltaic Modeling: Methodology and Validation
}

\section{Preprint}

Janine Freeman

National Renewable Energy Laboratory

David Freestate and Cameron Riley Electric Power Research Institute

William Hobbs

Southern Company Services, Inc.

Presented at the 43rd IEEE Photovoltaic Specialists Conference Portland, Oregon June 5-10, 2016

(c) 2016 IEEE. Personal use of this material is permitted. Permission from IEEE must be obtained for all other uses, in any current or future media, including reprinting/republishing this material for advertising or promotional purposes, creating new collective works, for resale or redistribution to servers or lists, or reuse of any copyrighted component of this work in other works.

NREL is a national laboratory of the U.S. Department of Energy Office of Energy Efficiency \& Renewable Energy Operated by the Alliance for Sustainable Energy, LLC

This report is available at no cost from the National Renewable Energy Laboratory (NREL) at www.nrel.gov/publications.

\section{Conference Paper}

NREL/CP-6A20-66465

November 2016 


\section{NOTICE}

The submitted manuscript has been offered by an employee of the Alliance for Sustainable Energy, LLC (Alliance), a contractor of the US Government under Contract No. DE-AC36-08GO28308. Accordingly, the US Government and Alliance retain a nonexclusive royalty-free license to publish or reproduce the published form of this contribution, or allow others to do so, for US Government purposes.

This report was prepared as an account of work sponsored by an agency of the United States government. Neither the United States government nor any agency thereof, nor any of their employees, makes any warranty, express or implied, or assumes any legal liability or responsibility for the accuracy, completeness, or usefulness of any information, apparatus, product, or process disclosed, or represents that its use would not infringe privately owned rights. Reference herein to any specific commercial product, process, or service by trade name, trademark, manufacturer, or otherwise does not necessarily constitute or imply its endorsement, recommendation, or favoring by the United States government or any agency thereof. The views and opinions of authors expressed herein do not necessarily state or reflect those of the United States government or any agency thereof.

This report is available at no cost from the National Renewable Energy Laboratory (NREL) at www.nrel.gov/publications.

Available electronically at SciTech Connect http:/www.osti.gov/scitech

Available for a processing fee to U.S. Department of Energy and its contractors, in paper, from:

U.S. Department of Energy

Office of Scientific and Technical Information

P.O. Box 62

Oak Ridge, TN 37831-0062

OSTI http://www.osti.gov

Phone: 865.576.8401

Fax: 865.576.5728

Email: reports@osti.gov

Available for sale to the public, in paper, from:

U.S. Department of Commerce

National Technical Information Service

5301 Shawnee Road

Alexandria, VA 22312

NTIS http://www.ntis.gov

Phone: 800.553 .6847 or 703.605 .6000

Fax: 703.605.6900

Email: orders@ntis.gov 


\title{
Using Measured Plane-of-Array Data Directly in Photovoltaic Modeling: Methodology and Validation
}

\author{
Janine Freeman*, David Freestate ${ }^{\dagger}$, William Hobbs ${ }^{\ddagger}$, and Cameron Riley ${ }^{\dagger}$ \\ ${ }^{*}$ National Renewable Energy Laboratory, Golden, CO, 80401, USA; ${ }^{\dagger}$ Electric Power Research Institute, \\ Palo Alto, CA, 94304, USA; ${ }^{\ddagger}$ Southern Company Services, Inc., Birmingham, AL, 35203, USA
}

\begin{abstract}
Measured plane-of-array (POA) irradiance may provide a lower-cost alternative to standard irradiance component data for photovoltaic (PV) system performance modeling without loss of accuracy. Previous work has shown that transposition models typically used by PV models to calculate POA irradiance from horizontal data introduce error into the POA irradiance estimates, and that measured POA data can correlate better to measured performance data. However, popular PV modeling tools historically have not directly used input POA data. This paper introduces a new capability in NREL's System Advisor Model (SAM) to directly use POA data in PV modeling, and compares SAM results from both POA irradiance and irradiance components inputs against measured performance data for eight operating PV systems.
\end{abstract}

Index Terms-irradiance, modeling, performance, plane of array (POA), PV, System Advisor Model (SAM), validation.

\section{INTRODUCTION}

There is little question that accurate photovoltaic (PV) system performance modeling is crucial to financing, verifying, and monitoring a PV system. However, accurate performance modeling requires high-quality irradiance input data. Historically, a combination of measured and modeled irradiance data has been used for such modeling, but as the PV industry matures, measured irradiance data is becoming more widely used. Global irradiance measured in the plane of the array (POA irradiance) is a promising measurement option: it is cheaper and easier than measuring beam or diffuse irradiance because it does not require equipment with moving parts, and, unlike global horizontal, it does not need to be transposed to the plane of the array. Research shows that this transposition can introduce errors ranging from a few percent to upwards of ten percent [1] - [4]. Matched POA reference cell data in particular has been shown to correlate better to measured performance data because of its similar response to spectral, angle-of-incidence, and diffuse irradiance effects [5] - [6].

Many project developers choose to measure only POA irradiance to achieve this balance between cost and accuracy. Unfortunately, popular PV modeling software has historically been unable to directly use POA data as input [7] - [9]. To respond to this gap, the National Renewable Energy Laboratory (NREL) has implemented a methodology to allow POA irradiance data to be used directly in the System Advisor Model (SAM) Detailed Photovoltaic performance model. NREL has tested this new capability in collaboration with the Electric Power Research Institute (EPRI) and Southern
Company Services, Inc. (SC) using field-measured POA and performance data for eight operating PV systems.

\section{MODEL IMPLEMENTATION}

Theoretically, using POA data as input to a PV module model is straightforward because the models ultimately use the global irradiance incident on the PV cells. In SAM, the most widely used PV module performance models are the California Energy Commission single diode model and Sandia PV Array Performance model, which both treat angleof-incidence (AOI) effects by reducing the beam portion of the POA irradiance incident on the PV cells to account for reflection by the module cover [10]. However, the actual module cover effects may be completely or partially accounted for in measured POA data, depending on the type of sensor used. For this reason, SAM offers two POA options: the "POA reference cell" option assumes that the measurement surface experiences the same AOI effects as the cells in the system and bypasses all AOI reductions in the module model. The "POA pyranometer" option assumes that the measurement surface does not experience any AOI effects and therefore applies the full AOI reductions to the incident beam irradiance. To calculate the incident beam irradiance for the latter option, SAM employs the POA decomposition model presented by Marion in Solar Energy [11]. (Fig. 1 illustrates the sub-models required for various input irradiance options.)

There are of course uncertainties in each of these AOI assumptions: (1) it is unlikely that a pyranometer experiences absolutely no cover effects, (2) if the POA reference cell is not properly matched to the selected PV technology, the actual module cover effects may be different than those measured, and (3) there is some uncertainty inherent in the POA decomposition model. This paper examines whether these uncertainties can introduce less error than the traditionally employed transposition models, assuming equal sensor quality between the two methods. If the POA sensors and traditional component irradiance sensors are not of equal quality or maintained equally, then it is likely that the higher quality input irradiance data would produce the best modeling results.

A final consideration in direct use of POA irradiance data is that, like the AOI corrections, there are a few other sub-models that require separate beam and diffuse components of the POA data. These sub-models include all of the shading models (both row-to-row shading and beam and diffuse shading from external tools or the $3 \mathrm{D}$ shading model), concentrating PV 


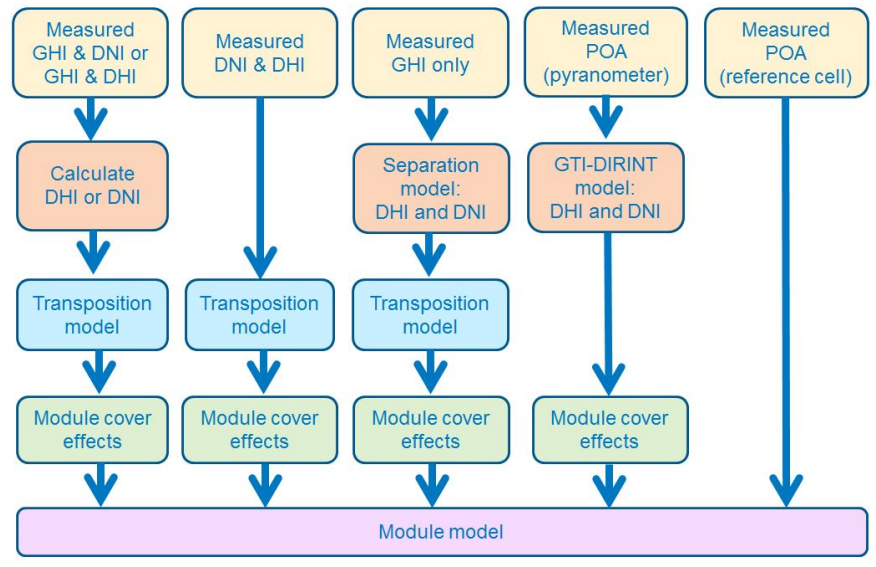

Fig. 1. Flowchart describing the models required for various input irradiance data options.

modeled using a diffuse utilization factor less than 1 in the simple efficiency module model, and the heat transfer module temperature model [10]. When any one of these sub-models is selected in conjunction with either of the two POA options, the POA decomposition model will be triggered so that these models may be applied to the correct component of the POA irradiance. None of the test cases described in this study utilized any of the aforementioned sub-models.

\section{COMPARISON Methodology}

In order to fully characterize using POA irradiance measurements directly in PV modeling, the method is compared not only to measured data, but also to the conventional method of using transposition algorithms. We simulated energy production for a given system using every possible combination of transposition models and irradiance input options within SAM, including both of the two new POA input options, and compared these predicted values to the measured energy for eight operating PV systems. The eight PV systems studied were selected based on the availability of system specifications, and of measured irradiance data concurrent with measured energy production. The systems represent a variety of geographic locations, climates, module types, tilts, azimuths, and tracking types. EPRI and Southern Company implemented quality control measures for both the measured irradiance and performance data for the systems that they modeled.

A summary of the systems studied and the irradiance data available for each system is shown in Table I.

Two metrics were selected to illustrate the differences between the various irradiance and transposition model combinations (which we will refer to as "methods"): the normalized root mean square error (RMSE) and the annual percent difference error, henceforth referred to as the annual error. Both error metrics are calculated with respect to measured data.
RMSE gives an indication of how well a simulation tracks hourly system performance, and is calculated according to:

$$
R M S E=\sqrt{\frac{\sum_{i=1}^{N}\left(p_{i}-m_{i}\right)^{2}}{N}}
$$

where $p$ is the predicted value, $m$ is the measured value, and $N$ is the total number of hours. For the RMSE results, each simulation was adjusted such that the annual predicted energy matched the annual measured energy of the system. This isolates the hourly variation in error, rather than skewing the RMSE with imperfect input loss assumptions (soiling, wiring losses, etc.). However, this also results in artificially low RMSE magnitudes; in this study, it is more relevant to compare the RMSEs to one another than to look at the absolute magnitudes.

Annual error is an important metric for predictive PV simulations, being the primary driver behind many financial decisions. Each simulation to calculate annual error uses all of the default loss assumptions in SAM version 2015.6.30, including a 5\% soiling loss.

$$
\text { AnnualError }=\frac{\sum p_{i}-\sum m_{i}}{\sum m_{i}} * 100 \%
$$

\section{RESULTS}

Fig. 2 and Fig. 3 show the normalized RMSE and annual error compared to measured data for eight systems, using four different methods: direct normal irradiance (DNI) \& global horizontal irradiance (GHI) inputs using the Hay-DaviesKlucher-Reindl (HDKR) transposition model, DNI \& GHI inputs using the Perez transposition model, and two methods that use the same POA data as input, one that applies the "POA Reference Cell" option in SAM and one that uses the "POA Pyranometer" option. Fig. 4 shows the annual error for a subset of the systems that had more irradiance data available. All three irradiance components (DNI, GHI, and diffuse horizontal irradiance -DHI) were measured at these five sites, making possible a more expanded comparison of irradiance input methods. Again, the same stream of POA data is run once through each of the two different POA input options in SAM.

For systems marked with (*), DNI was not actually measured at the site, but calculated from measured GHI. For systems marked with $(\dagger)$, POA was measured using a photodiode pyranometer, otherwise POA was measured using a thermopile pyranometer. Systems marked with $(\ddagger)$ are single-axis tracking systems, where all others are fixed-tilt.

\section{Discussion}

As we expect from the literature [5] - [6], the RMSE is smaller when using measured POA data than when using irradiance components and a transposition model for most of the systems. This is true for both photodiode and thermopile POA pyranometers, and for sites where all three irradiance components are measured as well as those where only GHI is measured. The improved RMSE for the POA options may 
TABLE I

Characteristics of Systems Studied and Irradiance Data Available for Each System

\begin{tabular}{|c|c|c|c|c|c|c|c|c|c|}
\hline System & Size $(\mathrm{kW})$ & Location & System Type & Tilt (degrees) & GHI & DHI & DNI & POA- photodiode & POA- thermopile \\
\hline$\overline{\text { EPRI1 }}$ & 19,400 & Southwest & Fixed tilt & 25 & $\begin{array}{l}\mathrm{x} \\
\end{array}$ & & & & $\begin{array}{l}\mathrm{X} \\
\end{array}$ \\
\hline EPRI2 & 18,000 & Southwest & Single-axis tracking & N/A & $\mathrm{x}$ & & & & $\mathrm{x}$ \\
\hline EPRI3 & 10 & West & Fixed tilt & 35 & $\mathrm{x}$ & $\mathrm{x}$ & $\mathrm{x}$ & $\mathrm{x}$ & \\
\hline EPRI4 & 10 & West & Fixed tilt & 35 & $\mathrm{x}$ & $\mathrm{x}$ & $\mathrm{x}$ & $\mathrm{x}$ & \\
\hline EPRI5 & 8360 & Southeast & Fixed tilt & 25 & $\mathrm{x}$ & & & $\mathrm{x}$ & \\
\hline $\mathrm{SC} 1$ & 2.4 & Southeast & Fixed tilt & 30 & $\mathrm{x}$ & $\mathrm{x}$ & $\mathrm{x}$ & & $\mathrm{x}$ \\
\hline $\mathrm{SC} 2$ & 2.4 & Southeast & Single-axis tracking & N/A & $\mathrm{x}$ & $\mathrm{x}$ & $\mathrm{x}$ & $\mathrm{x}$ & \\
\hline $\mathrm{SC} 3$ & 2.4 & Southeast & Fixed tilt & 30 & $\mathrm{x}$ & $\mathrm{x}$ & $\mathrm{x}$ & $\mathrm{x}$ & \\
\hline
\end{tabular}

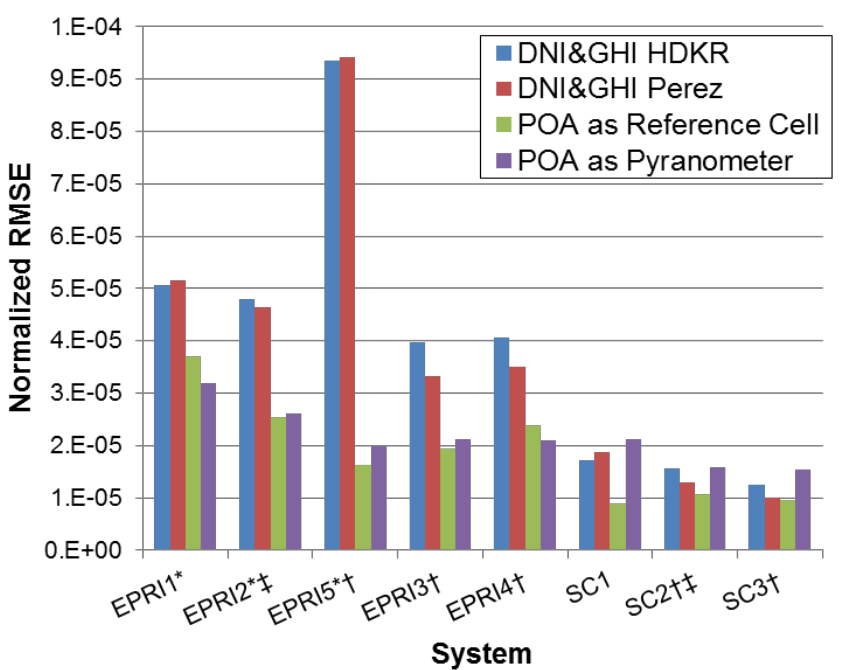

Fig. 2. RMSE for eight systems using four irradiance input methods.

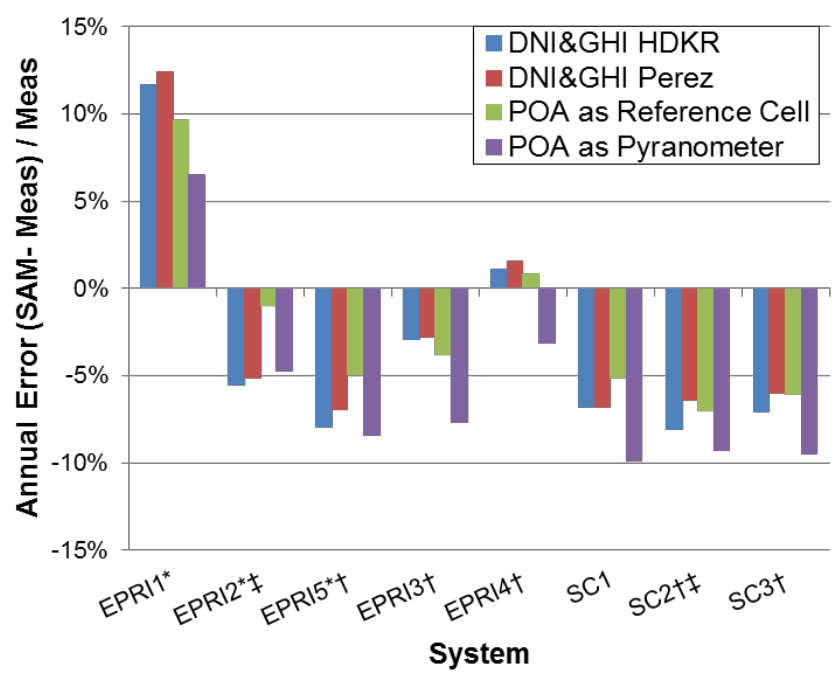

Fig. 3. Annual error for eight systems using four irradiance input methods.

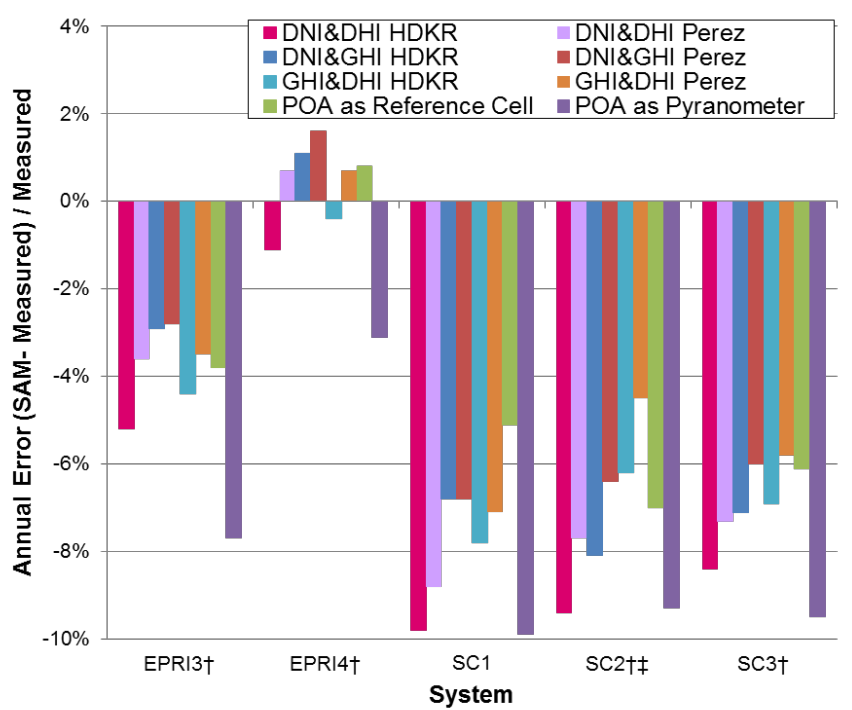

Fig. 4. Annual error for five systems using eight irradiance input methods.

be due to the fact that there is no error introduced by the transposition model. In the case of the POA pyranometer option in SAM, the POA is actually decomposed into beam and diffuse components, which has the potential to add some error, but here there are two possible reasons for improved RMSE: (1) the decomposition model may introduce less error than the transposition model, or (2) error in the calculation of the module cover effects due to imperfect decomposition may be smaller than the error in the transposition model. Another potential contributing factor for the lower RMSE of both POA options could be decreased cosine response. Although pyranometers are designed to have as close to a perfect cosine response as possible, many only specify an uncertainty up to an $\mathrm{AOI}$ of $80^{\circ}$; AOIs in excess of $80^{\circ}$ occur far more often in horizontally-mounted pyranometers than tilted pyranometers.

By far the more interesting result demonstrated in Fig. 2 , though, is that for several systems, the same stream of POA data has lower RMSE when treated as a reference cell than when treated as a pyranometer, despite the fact that the POA is measured with a pyranometer for all eight systems. Furthermore, in some cases the pyranometer POA 
data has worse RMSE than traditional methods when treated as a pyranometer, but better RMSE than traditional methods when treated as a reference cell. These unexpected results do not correspond to the type of POA sensor used (thermopile or photodiode). Since the only difference between these two results is the application of module cover effects, this indicates that we need to better understand cover effects for both POA sensors and modules themselves. Module cover losses may be smaller or more constant than they are generally assumed to be, or pyranometer cover effects may be more significant than we realize.

Unlike the RMSE results, the annual error results in Fig.s 3 and 4 do not show that one method outperforms the others for the majority of systems. As expected, the POA pyranometer option consistently predicts lower energy than the POA reference cell option for the same POA data because the reference cell is not subjected to module cover effects. This frequently makes the POA pyranometer option the lowest predicted energy, but even that is not universally true, as seen for system SC2 in Fig. 4 and system EPRI2 in Fig. 3. The two POA model options sometimes predict higher energy than the transposition model options and sometimes predict lower energy, sometimes have larger error and sometimes have the smallest error- this does not appear to correspond to any particular system characteristic. The two POA options perform within the same range of error as the transposition model options for all systems (especially demonstrated in Fig. 4), although the POA treated as a reference cell frequently produces errors that are more consistent with the traditional methods.

It is important to properly interpret the results of Fig.s 3 and 4. One method resulting in the lowest annual error for a given system does not necessarily mean that it most accurately models the system; rather, it shows that the combination of the method's accuracy and the loss assumptions made for that system results in the closest energy prediction on an annual basis. This nuance renders the annual error results instructive on a relative scale, but not indications of absolute accuracy of a method. For many systems in our study, every simulation underpredicts measured energy, suggesting either that the loss assumptions are too high for the actual site conditions, or that the input irradiance sensors were reading lower than reality, potentially indicating a quality control issue. Conversely, every simulation of EPRI1 overpredicts measured energy, suggesting that the system losses are higher than SAM's default assumptions or that some system outages escaped the quality control measures. The uncertainty in the input loss assumptions and potential quality control issues make it impossible to determine which method is actually providing the most accurate annual energy prediction.

\section{Summary AND Future WORK}

This initial comparison of the newly implemented POA irradiance input options in SAM shows that they perform comparably to more conventional input methods for eight systems. The RMSE is improved for most systems by using the
POA input options, and the annual error falls within the same range as the traditional methods, especially when compared to all possible combinations of irradiance component inputs for a subset of systems that had more measured components. This demonstrates that the use of POA data as an input to PV models can give meaningful energy production estimates, which may help project developers achieve a balance between cost and accuracy in measuring irradiance data for PV modeling. POA data measured by a pyranometer but treated by SAM as a reference cell (e.g., not subjected to module cover effects) frequently results in lower RMSE and annual error than the same POA data treated as a pyranometer, suggesting that future work should investigate cover effects as they relate both to POA sensor devices and PV modules themselves. Finally, more effort should be made to understand and reduce the uncertainty in the loss assumptions and quality control measures for PV modeling in general so that differences between various modeling options may be more readily identified.

\section{ACKNOWLEDGMENT}

This work was supported in part by the U.S. Department of Energy under Contract No. DE-AC36-08-GO28308 with the National Renewable Energy Laboratory. Funding provided by the U.S. DOE Office of Energy Efficiency and Renewable Energy Solar Energy Technologies Program.

\section{REFERENCES}

[1] M. Lave, W. Hayes, A. Pohl, and C. Hansen, "Evaluation of global horizontal irradiance to plane-of-array irradiance models at locations across the United States," IEEE Journal of Photovoltaics, vol. 5, issue 2, p. $597-606,2015$.

[2] C. Gueymard, "Direct and indirect uncertainties in the prediction of tilted irradiance for solar engineering applications," Solar Energy, vol. 83, issue 3, p. 432-444, 2009.

[3] A. Noorian, I. Mooradi, and G. Kamali, "Evaluation of 12 models to estimate hourly diffuse irradiation on inclined surfaces," Renewable Energy, vol. 33, issue 6, p. 1406-1412, 2008.

[4] P. Loutzenhiser, H. Manz, C. Felsmann, P. Strachan, T. Frank, and G. Maxwell, "Empirical validation of models to compute solar irradiance on inclined surfaces for building energy simulation," Solar Energy, vol. 81, issue 2, p. 254-267, 2007

[5] L. Dunn, M. Gostein, and K. Emergy, "Comparison of pyranometers vs. PV reference cells for evaluation of PV array performance," in 38th IEEE Photovoltaic Specialist Conference, p. 2899-2904, 2012.

[6] Atonometrics white paper, "Best practices in irradiance measurement for PV arrays: a brief literature survey," atonometrics.com, Document number 880026, Revision A, 2012.

[7] A. Mermoud, PVsyst help forum, "My transposed POA values don't match the imported values," Available: http://forum.pvsyst.com/viewtopic. php?f=18\&t=40, 2012. Accessed Jan 2016.

[8] Valentin Software, PV*SOL FAQ, Available: http://shop. valentin-software.com/FAQ-PV-SOL.html,2016. Accessed Jan 2016.

[9] Helioscope help documentation, "Irradiance calculations," Folsom Labs, Available: https://www.folsomlabs.com/modeling/environment/ irradiance_calculation, 2016. Accessed Jan 2016.

[10] P. Gilman, "SAM photovoltaic model technical reference," NREL technical report TP-6A20-64102, 2015.

[11] B. Marion, "A model for deriving the direct normal and diffuse horizontal irradiance from the global tilted irradiance," Solar Energy, vol. 122, p. 1037-1046, 2015. 